\title{
ЛОГИСТИКА ГЕОПОЛИТИКИ
}

\author{
А. Г. ЕВСТАФЬЕВ \\ Глобальные трансформации и Россия: \\ источники конфронтации и перспективы \\ глобального взаимодействия
}

\author{
Дмитрий Геннадиевич Евстафьев, канд. полит. наук, \\ профессор Департамента интегрированных коммуникаций \\ Факультета коммуникаций медиа и дизайна \\ Национального исследовательского \\ университета - «Высшая школа экономики» \\ E-mail: devstafiev@hse.ru; estd1212@yandex.ru
}

\begin{abstract}
Аннотация. Обострение отношений России и Запаца, в основе которых ^ежат отношения России и США, является не только результатом пропаганды, но и отражает ряА конфрликтных реальностей современной системы межАународных политических и экономических отношений, в развитии которых Россия может сыграть значительную роль, которая будет в наибольшей степени проявляться на этапе формирования архитектуры новой системы глобальных отношений. Эта система явно будет сушественно отличаюшейся - особенно в институциональном плане - от той, что сушествовала в последние 30 ^ет. В таких условиях враждебная позиция России по отношению к интересам Запада рассматривается как один из наиболее важных рисков и как фрактор, способный изменить стратегический расклаА сил. Участие России, хотя бы и во вспомогательном качестве, в ряде значимых глобальных процессов способно сохранять сушествуюшее противоборство в рамках модели «игры с ненулевой суммой».

Ключевые слова: Россия, США, новая «холодная война», глобализация, военная конфрронтация, глобальная фринансовая система, энергетическая безопасность, глобальные институты.
\end{abstract}

\section{ВМЕСТО ВВЕАЕНИЯ: КОНТУРЫ ПРОБАЕМЫ}

Отношения России и Запада обычно рассматриваются как один из центральных факторов международной обстановки. Такой подход предполагает понимание конфронтационной политики в отношении России в качестве самодостаточного компонента глобальной политики. Он «вырывает» политику Запада и ответные действия России из более широкого глобального контекста, искажая тем самым картину происходящего даже в случае осознания всех сложностей транзита от преимущественной монополярности к полицентричности; если же такое осознание не имеет места, то формируется еще более искаженная картина ${ }^{1}$. «Россиецентризм» не дает возможности оценить масштабы происходящих в мире событий и роль противостояния России

\footnotetext{
${ }^{1}$ Доминирует подход, основывающейся на той посылке, что ключевой причиной развития полицентричности, в перспективе способной перерасти в многополярность, является ослабление США и кризис лидерства Америки, причины которого интерпретируются в зависимости от политической позиции того или иного автора [16].
} 
и Запада, которое находится в состоянии распада «коллективности», в глобальных процессах. Поэтому и ответ на вопрос о том, почему приходящиеся на долю России 1,6 \% глобального ВВП (или около $4 \%$ по паритету покупательной способности) ${ }^{2}$ оказываются настолько важными для мировой политики и даже для отдельных сегментов глобальной экономики, звучит, как правило, несколько неубедительно.

Как представляется, решающим фактором является здесь способность США и Китая удерживать двусторонние отношения и их наиболее значимые глобальные проявления в рамках неконфронтационной модели внутри существующей единой системы глобальной экономики - возможно, трансформируя политический аспект глобализации. При таком понимании Россия выступает в качестве дополнения к китайским военно-силовым и геоэкономическим возможностям [22]. Но и это не объясняет накала политического, а теперь уже и военнополитического давления на нашу страну. Тем не менее отношения с Россией важны, особенно с точки зрения краткосрочных политических процессов, которые являются фоном для подготовки к стратегическим изменениям. Но в фокусировании многих конфронтационных процессов на России есть и очевидный среднесрочный (как минимум) контекст.

Современный мирстоит наподступахксерьезной реконфигурациисистемымировой экономики и глобальной политики. Политическая напряженность вокруг России выглядит незначительной и чрезмерной пропагандистски акцентированной по сравнению с потенциалом переконфигурации основ глобальной политики. Но связанные с Россией кризисы и информационные всплески могут являться лишь некими пре-шоками, предшествующими началу глобальных трансформаций. Западные социальные философы признают, что в понимании мира, доминировавшем в период монополярности, господствовало упрощенное представление о принципах глобальной взаимозависимости ${ }^{3}$. Взаимозависимость, особенно экономическая, рассматривалась просто как свойство всей системы, а не как продукт внутренних связей между ее компонентами, как некая базовая данность, которая будет сохраняться при всех трансформациях системы. Формирующиеся парадигмы глобальной политики существенным образом отличаются от того, каким видели мир классики западной политологической мысли, причем даже те, кто, как С. Хантингтон, признавали невозможность не только «вечной», но даже просто долговременной стабильности. Начинают, похоже, сбываться казавшиеся экзотическими прогнозы о возможности своего рода квантовизации внешней политики [1]. Это свидетельствует о глубокой системной деструкции институциональных основ мировой политики и регулятивных, в частности саморегулятивных, механизмов мировой экономики.

\section{СТРУКТУРА ВЕКТОРОВ КОНКУРЕНЦИИ В СОВРЕМЕННОМ МИРЕ}

Ни один из активных участников современной мировой политики сейчас не способен в полной мере бороться за доминирование. США уже с трудом удается поддерживать в некризисном режиме достигнутый уровень глобального влияния, что говорит об исчерпании возможностей использовать «мягкую силу» (что бы под ней ни понималось) в качестве инструмента поддержания американоцентричности в мировой политике и экономике. Китай еще не способен претендовать на роль симметричного по потенциалу «полюса» в гипотетической системе подлинной многополярности. Центральная коллизия современной системы международных отношений сводится к тому, насколько конкуренция США с Китаем будет и дальше оставаться внутрисистемной и происходить в рамках модели конфликта с «ненулевой суммой» или же США достигли предела в способности предоставлять КНР дополнительное операционное пространство. Пропагандистски сфокусированные действия Д. Трампа в отношении КНР говорят в пользу второго вариант, хотя в целом политика нынешней администрации отличается непоследовательностью. К тому же конкуренция США и КНР происходит не в вакууме, а в меняющемся пространстве глобальной политики и экономики, где действуют и другие

\footnotetext{
${ }^{2}$ Вариант расчета ВВП по долларовому эквиваленту эффективно отражает роль той или иной страны в мировой экономики. Расчет по ППС скорее эффективен для оценки динамики внутреннего социально-экономического развития. В рамках данной статьи приоритетным является, безусловно, расчет по долларовому эквиваленту.

${ }^{3}$ Как пример можно привести удивительно глубокую работу итальянского социолога и политолога Данило Дзоло 1992 г. «Демократия и сложность. Реалистический подход» [3]. Д. Дзоло указывает на зависимость переменных, компонентов системы друг от друга как на ключевую функцию трансформации системы взаимозависимости [3, с. 30].
} 
субъекты, что дополнительно осложняет ситуацию.

В глобальной политике уже присутствует разновекторность, но еще нет многополярности, для которой необходимы подлинно глобальные экономические основания. Развивается то, что можно было бы назвать «секторальной полицентричностью», реализующейся через среднесрочные социально-экономические процессы, трансформирующие глобальную экономику и политику, но до известной степени параллельные процессам структурирования полицентричного мира на национально-государственном уровне. Секторальную «полицентричность» можно предварительно определить как утрату США функиий безусловного глобального гегемона в определенных относительно узких секторах (пространствах) мировой политики и экономики или в значимых для системы международных политических и экономических отношений географических пространствах («макрорегионах)).

И если в формате формирования классической многополярности, даже при ее транзите через полицентричность, у России имеются относительно слабые шансы на получение статуса «полюса» силы и влияния, то в рамках «секторальной полицентричности» значимость России как игрока на мировой арене возрастает.

О каких же наиболее значимых глобальных процессах мы можем говорить, и почему участие России в них важно?

\section{НАРАСТАНИЕ ПОТРЕБНОСТИ В ПЕРЕСТРОЙКЕ ФИНАНСОВОЙ СИСТЕМЫ}

Последние полтора года продемонстрировали высокий уровень активности в обсуждении и превращении в экономически пригодные системы новых форматов и возможностей цифровых финансовых коммуникаций и связанных с ними инвестиционных обстоятельств.

Просто перечислим:

• Переход ксанкционной политике с использованием фактора глобальной финансовой взаимозависимости и доминирования в инвестициях долларовых расчетов.

- Девальвационные войны, направленные на создание ситуации преимущественной поддержки экспорта.

- Устойчивый интерес к криптовалютам и денежным суррогатам, понимаемым как средство частичного обхода долларовой системы. Налицо замедление процесса отказа от наличного денежного обращения.

- Не слишком быстрая, но последовательная апробация системы нефтяных фьючерсов в КНР [4], свидетельствующее о том, что проект носит долгосрочный и реальный характер, а не связан с попытками оказать на США пропагандистские давление.

- Разработка и предварительное тестирование клиринговых системы на основе принципов «распределенного реестра». Важно отметить, что такого рода системы в наибольшей степени применимы в документообороте, связанном с обеспечением торговых операций.

- Альтернативные системы персональных платежей. Наиболее интересны система “Union Раy", использование внутренней национальной платежной системы в Иране, а также опыт форсированного внедрения платежной системы «Мир».

- Ренессанс концепции внутренних офшоров как инструмента стимулирования инвестиционных процессов и вывода части национальных экономических пространств из-под жесткого национального и наднационального регулирования.

Возникает вопрос: не являются ли наблюдаемые нами процессы признаками распада глобального финансово-инвестиционного мейнстрима, на котором основывалась политика строительства американоцентричных регулятивных систем и институтов, пик использования которых проявился, в том числе, и в ходе введения против России экономических санкций? По сути, санкции против России были первым случаем использования глобального регулятивного механизма в глобальном же масштабе против страны, обладающей возможностями влиять на критические сегменты мирового рынка. И это продемонстрировало как возможности таковой системы, так и ее недостатки и точки уязвимости. 
Современный мир - во всяком случае, большинство крупнейших игроков мировой экономики, не исключая и США, - готовится к деглобализации финансовых коммуникаций и к возникновению, как минимум, ограниченной финансовой анклавности. Это отражает высокий уровень восприятия угрозы глобального или, как минимум, субглобального финансового кризиса, который в нынешних условиях может оказаться существенно более разрушительным, нежели кризис 2008-2009 гг. Это уже в среднесрочной перспективе ставит на повестку дня постепенный переход от «простых денег» К «сложным» финансовым инструментам, основанных на усложненных и разноуровневых алгоритмах доступа к финансовым ресурсам ${ }^{4}$.

Основой системы «сложных денег» являются механизмы хеджирования операционных и инвестиционных рисков. Россия вряд ли может рассматриваться как решающий компонент альтернативных систем финансовых коммуникаций, хотя опытом своей деятельности в состоянии глобализированных международных санкций и апробирует некие финансовые механизмы, которые затем могут быть использованы в более широком контексте. Россия может стать важнейшим участником механизмов хеджирования финансовой деятельности как на уровне классической геополитики (территория Россия с военной точки зрения пока остается неуязвимой для военного давления со стороны Запада, возобновляются элементы классического сдерживания), так и на уровне формирования пула ликвидных ресурсов. Россия оказывается одним из наиболее активных участников этих процессов, и дело здесь не только и не столько в запуске и первичной отработке процессов глобализации Национальной платежной системы. Россия играет большую роль и в определении наиболее приемлемых и эффективных технологий распределенного реестра, который, как уже очевидно, будет основой системы оборота «сложных» финансовых ресурсов. Россия смогла за прошедшие четыре года обеспечить существенно более высокий уровень защищенности своего финансового рынка, не прибегая при этом к мобилизационной модели. С другой стороны, Россия до известной степени утратила стимулы к соблюдению взятых на себя обязательств в сфере глобальных финансов и обладает ныне беспрецедентной свободой рук в сфере финансов. Несмотря на то что объемы финансового оборота не столь велики, Россия способна предложить технологии, которые при необходимости могут быть востребованы относительно широким кругом пользователей.

Это обстоятельство неприемлемо для США не только по причине возможного перетягивания Россией «на себя» значимых финансовых потоков, что маловероятно, хотя и возможно, особенно в сфере рискового капитала. Угроза для США состоит в возможности возникновения в архитектуре мировой финансовой системы неконтролируемых сегментов. Ведь апробированные в этих сегментах технологии могут быть легко масштабированы, что станет шагом к разрушению американской монополии в финансовой системе.

«Новая логистика» как элемент будущей глобальной экономической архитектуры. Основой той экономической и политической эпохи, которая сейчас считается уходящей, справедливо считается глобальная логистика, построенная натрансокеанских коммуникациях, безопасность и устойчивость которых обеспечивалась США как через потенциал военно-морских сил, так и через различные логистические и финансово-инвестиционные (например, глобальную систему страхования рисков в перевозках) инструменты. Сила данной системы вытекала из ее комплексности и глобальности, на которой формировалась глобальная логистическая рента, ставшая одним из источников инвестиционных процессов в ряде глобальных городов. Особенностью этой логистической системы была ее способность до известной степени действовать вне оглядки на принцип государственного суверенитета, становясь одной из опор пресловутого «сетевого мира», в котором принцип суверенитета считался излишним. Сейчас мы видим реализацию принципиально иных тенденций в глобальной логистике, которые не просто могут привести к перераспределению логистической ренты между ключевыми игроками (как, например, это было с Транссибирским логистическим маршрутом в конце 1990-х гг. и первоначальными вариантами Великого шелкового пути), но и создать принципиально новую систему геоэкономических отношений.

\footnotetext{
4 Концепция «сложных денег», одним из проявлений которой стала используемая для синдицированных кредитов технология «распределенного реестра» («блокчейн»), во многом отражала неспособность «простого» финансового мира, основанного на принципе «одного окна», выполнять свои функции как инструмента кредитно-инвестиционного обеспечения глобализированного, но равномерного экономического роста [13, с. 200]. Регионализация экономического роста неизбежно вызвала к жизни идею регионализации финансового пространства, а главное - поиска приемлемых для стран, не имеющих решающего голоса в мировых финансах, инструментов хеджирования рисков в мировой торговле.
} 
Количество новых логистических проектов, которые потенциально могут иметь глобальный эффект, за последние годы существенно выросло. Помимо находящихся на слуху проектов глобальных коридоров «Китай-Европа» и «Север-Юг», которые стоит рассматривать не только как явления экономические, но и как фактор социокультурных изменений регионального или даже субглобального масштаба 5 , следует обратить внимание на следующие проекты:

- Трансафриканский комплексный логистический коридор; новый трансокеанский канал через Никарагуа;

- Трансбирманский коридор;

- Трансаравийский газотранспортный маршрут и система «южных» газовых коридоров; расширение логистических мощностей и индустриализация зоны Суэцкого канала;

- Северный морской путь.

При реализации даже одних только этих логистических проектов возникнет частично взаимоувязанное, в том числе - и черезтерриторию России (Южно-Уральский логистический узел, а также Прикаспийское геоэкономическое пространство) новое экономическое пространство. Мировая экономика, оставаясь в рамках «морской» парадигмы, получит совершенно иные характеристики по темпам грузоперевозок, рисковости и инвестиционно-финансовой составляющей, включая механизмы извлечения и реинвестирования логистической ренты. Но одновременно в ряде потенциально социально-экономически дестабилизируемых регионов возникнет принципиальной новая конфигурация обеспечивающих новые хозяйственные и инвестиционные модели экономических интересов, функционирующих на иных, чем прежде, принципах рентабельности и механизмах взаиморасчетов.

Россия может быть включена, как минимум, в несколько таких проектов, получая под свой контроль полностью Северный морской путь и приобретая частичное, но значимое присутствие в коридорах «Север - Юг» и «Китай - Европа», а за счет своего силового потенциала - «контрольный пакет» в трансаравийских газотранспортных маршрутах. Это делает Москву значимым игроком в глобальной логистике, способным определить исход «торгов» игроков «первого ряда» - США и Китая. Логистическое влияние России сейчас может быть оценено как превышающее влияние ЕС. Без, как минимум, нейтралитета России не могут быть осуществлены критические для глобальной логистики и энергетики проекты.

Воссоздание локализованных индустриальных ядер. Все страны, претендующие, как минимум, на сохранение своего статуса в мировой экономике, а значит, как правило, и в политике, предпринимают попытки воссоздания промышленных ядер в пределах своей национальной территории. Наиболее заметной является «индустриализация Трампа», прямо противоположная вектору развития американской экономики последних 25 лет. Но «индустриализация Трампа» является столь же социальным, сколько и экономическим явлением, и направлена на смягчение (как минимум - на «примораживание») региональных и социальных диспропорций, которые вполне проявились на президентских выборах 2016 г.

Это же характерно и для других стран современного «западного мира». Германия отказалась от постиндустриальной трансформации - во всяком случае, на среднесрочную перспективу. То же самое касается и Италии. Нет признаков продолжения постиндустриализации в Японии [6]; не заметно пока и признаков комплексного внедрения механизмов «четвертой промышленной революции», хотя отдельные ее компоненты, например максимальная цифровизация сервисных и логистических компонентов, внедряются активно [5], хотя и с крайне сложным социальным эффектом. Процессы, которые принято считать составными частями «четвертой промышленной революции», пока не обеспечивают желаемой технологическо-индустриальной синергии.

Однако на фоне растущей востребованности идеологии новой индустриализации, хотя бы и в фантомной форме так называемой «четвертой промышленной революции», встает вопрос о функциях городов в современной экономике. Это ставит под сомнение всю идеологию «нового

5 Поскольку эти транспортные коридоры соединяют «большие» цивилизационные пространства, в которых господствуют различные по типу и принципам организации социокультурные парадигмы, которые проявляются и в политических практиках. Логика наполнения логистических коридоров (первого и второго «изводов Великого шелкового пути, пути «Из варяг в греки») не только товарами, но и идеями, потребительскими стереотипами, моделями социальных институтов, которые до известной степени противостоят традиционным для данных пространств социальным институтам и институтам управления и политической организации, является естественным и неизбежным процессом [15]. 
урбанизма», которая является частью концепции «сетевого мира» и которая реализовывалась с опорой на транснациональные финансово-инвестиционные анклавы (глобальные города). Глубокая деиндустриализация городского пространства начала создавать для глобального развития ощутимые социальные, а как следствие - и политические риски, связанные с избыточными затратами для обеспечения социальной стабильности в крупных городских агломерациях.

Пока не существует однозначно оформившейся лидерской технологической парадигмы, которая могла бы стать инвестиционным фокусом, как это было во второй половине 1990-х гг., когда таким инвестиционным фокусом стали компьютерные технологии. Данный технологический цикл продержался в инвестиционном обороте более 20 лет и стал основой для возникновения информационного общества нового типа, которое полностью соответствует парадигме постиндустриального общества. Сейчас ничего сравнимого по социальной безальтернативности и инвестиционному потенциалу не просматривается. Не исключено, что мир стоит на пороге практической реализации многовекторности технологического развития и мозаичности инвестиционных циклов.

Для России также характерна попытка перевода импортозамещения на более сложную комплексную модель, которая включает перенос основных точек монетизации в технологических цепочках внутрь России. Обращает на себя внимание попытка реализации более сложных моделей экспортной деятельности. Россия, конечно, не становится конкурентом крупнейших технологических держав на важнейших платежеспособных рынках, но сокращает доступность собственного рынка и рынков государств, связанных с ней политическими отношениями (по ряду сегментов промышленности - до 300 миллионов потребителей) для крупнейших производителей, прямо или косвенно аффилированных с ведущими государствами мира.

Значимость позиции России в процессах реиндустриализации заключается в ее принципиальной способности встроиться практически в любую технологическую волну (включая и робототехнику, хотя по этому направлению позиции России пока слабы), подкрепив ее ресурсами и инженерными возможностями и тем самым принеся конкурирующей технологической модели дополнительные бонусы. Россия одновременно осуществляет действия как в рамках второй промышленной революции, так и пытается обозначить наличие заделов в четвертом уровне, хотя это пока удается преимущественно на декларативном уровне и с чрезмерными коррупционными издержками.

Сравнительно - по отношению к прогнозам - успешное, если учитывать масштабы проблемы, развитие «импортозамещения» в России, прежде всего не столько на уровне конечного продукта, сколько на уровне импортозамещения компонентов и материалов, показывает потенциальную способность России крешению задач частичной индустриализации в пределах традиционных индустриальных ядер - естественно при условии снижения уровня коррупции. Вопрос на будущее заключается в способности России формировать новые индустриальные «ядра» в расчете на технологии «четвертой промышленной революции» или их дериваты («индустриальные гринфилды»), сохранив относительную социально-экономическую стабильность в пространстве «старой индустриализации». Это достижимо только через включение в процессы базовой индустриализации (Африка) и второй индустриализации (Ближний Восток, Индия) развивающегося мира. Но это требует прямой межгосударственной конкуренции с ключевыми игроками в мировой экономике с использованием тех инструментов, которые у России имеются, и тех системных отношений, которые Россия может выстроить с ведущими игроками глобальной политики по другим вопросам. Сохранение России в качестве активного участника процессов новой глобальной индустриализации, хотя бы в качестве игрока «второго ряда», является условием сохранения влияния Москвы в мировой политике и экономике. Этот вектор является очевидным приоритетом развития страны на ближайшее время.

Борьба за «новую энергетику». Мировой энергетический рынок в том виде, в каком он сформировался в начале 1990-х гг., завершает свое существование, хотя количество еще явно не перешло в качество. Роль России в данном случае неоспорима и проявляется хотя бы в том, что ее участие в договоренностях традиционных институтов, регулирующих рынок (ОПЕК), помогло сохранить их дееспособность. Но речь сейчас идет о перспективной архитектуре глобального энергетического рынка, причем как с технологической, так и с операционной точек зрения. 
Отсутствие прорывных технологических решений является сдерживающим фактором глобального экономического и социального развития, причем его значение будет усиливаться. В развитии процессов в глобальной энергетике мы наблюдаем три взаимно пересекающихся процесса: во-первых, поиски новой технологической платформы, которая дала бы возможность выйти за существующие сейчас ценовые (инвестиционные) и технологические рамки. Речь идет, прежде всего, о поисках глобальной технологической альтернативы в энергетике. То концептуально монопольное положение, которое имели так называемые «альтернативные источники энергии», в том числе и за счет прямого и довольно грубого использования административного ресурса в рамках идеологически обусловленных решений, сейчас размывается. «Альтернативные источники энергии» в глобальном масштабе за пределами идеологически маркированного ареала - ЕС - находятся в состоянии жесткой конкуренции с другими энергетическими технологиями. И эта борьба будет, вероятно, нарастать, что очевидно по ситуации, например в США, где вопросы обновления энергетической базы являются исключительно важными как для внутреннего развития, так и для американской внешнеэкономической стратегии.

Во-вторых, происходит усиленная реструктуризация глобального энергетического рынка, направленная на то, чтобы принципиально изменить его структуру, создавая в нем принципиально новые сегменты с иным, чем раньше, ценообразованием. В частности, на наших глазах возникли глобально значимые сегменты неклассических углеводородов, сжиженного природного газа или альтернативных источников энергии, в которых ценообразование ведется на других принципах, нежели на рынке, где доминировали классические углеводороды. И значение этих сегментов будет, похоже, расти.

В-третьих, энергетические ресурсы становятся привлекательной точкой не только для приложения инвестиций (энергетическая «рента» относится к легко монетизируемым и извлекаемым видам финансовых ресурсов в отличие от финансового сектора, где «рента» будет оставаться во многом каптивной, почти неизвлекаемой, используемой внутри системы и выводимой за ее пределы лишь с тем или иным дисконтом), но и политических, что и доказало развитие ситуации вокруг проблематики энергобезопасности Европы. Опыт легитимизации внедрения в экономический вопрос о структуре энергобаланса политической составляющей является вполне тиражируемым.

Как результат сочетания этих трех факторов энергетический рынок начинает действовать во все более деэкономизированной парадигме, когда стратегические решения принимаются не на основе просчета экономической выгодности тех или иных моделей и/или технологий, а на основе некоего стратегического видения перспектив развития. Политически мотивированным были и решение о форсированном развитии индустрии сланцевых нефти и газа в США, и о замораживании разработок сланцевых углеводородов в Китае. Участники рынка постоянно демонстрируют готовность условно «потерять» во влиянии и доходах сейчас, чтобы получить выгодные позиции для присутствия на энергетическом рынке «завтра», а некоторые страны, обладающие высокой уровнем экономический устойчивости, например Китай, и «послезавтра». Этим, в частности, и объясняется поведение Китая в диалоге с поставщиками энергоресурсов, включая как Россию, так и США.

С другой стороны, отсутствие новой в технологическом плане энергетической платформы становится одним из наиболее значимых ограничителей глобального экономического роста, в частности, за счет невозможности существенно расширить социально обусловленное потребление. В таких условиях длительное сохранение неэкономически обусловленной парадигмы в глобальной торговле энергоносителями будет проблематичным.

Россия оказывается одним из наиболее значимых факторов в развитии данного направления. И это связано не только и не столько с ее ролью в торговле классическими углеводородами, хотя в этой сфере Россия будет оставаться важнейшим фактором. Это связано с активным и не всегда предсказанным внедрением России в новые энергетические сферы, такие, например, как СПГ. Относительно быстрая адаптация российской нефтегазовой промышленности к спотовым системам торговли углеводородами оказалась неожиданной для ее партнеров и создала новую ситуацию, например на европейском энергетическом рынке, который планировалось рекартелизировать без учета интересов Москвы. Россия остается потенциально и одним из наиболее значимых игроков на рынке неклассических (сланцевых) углеводородов и может реализовать этот потенциал в период 
после 2030 г., что в целом совпадает с глобальными трендами. Глобальная энергетика до 2025 г., как минимум, будет оставаться преимущественно «углеводородной» при доминирующем значении классических углеводородов. А после 2025 г., вероятнее всего, следует ожидать транзита к неклассическим углеводородам, вокруг чего возможна также некоторая политическая и военносиловая турбулентность. Признаки подготовки к этому транзиту можно сейчас наблюдать в действиях Китая, активно скупающего американское «сланцевое наследство». Нельзя забывать и продемонстрированную Россией в ходе операции по стабилизации в Сирии способность к управлению рисками в макрорегионах, связанных с транспортировкой углеводородов, из чего рядом потенциальных игроков рынка были сделаны надлежащие выводы и не только применительно крегиону Ближнего и Среднего Востока. Покаединственной видимой уязвимостью, ограничивающей потенциал влияния России, является относительная слабость присутствия в повестке дня разработки новой и глобальной тиражируемой энергетической платформы. Но это обстоятельство может негативно проявиться только в среднесрочной перспективе.

Глобальная социальная реструктуризация. Кризис социальной модели глобализации. Глобальные процессы свидетельствуют о полноценном кризисе сложившихся в период поступательной глобализации системы общественных институтов («гражданское общество постмодерна») как в развитых, так и в развивающихся странах. Социальная атомизация, затрагивающая урбанизированные агломерации, становится тяжким глобальным бременем, которое ограничивает возможности глобального экономического роста. В таких условиях признается невозможность дальнейшего проведения политики догоняющей социальной модернизации.

Кризисные явления, связанные с социальными вопросами и последствиями социальной атомизации и форсированной постиндустриализации на фоне активного развития различных социально-вспомогательных механизмов (информационных и социальных сервисов), начинают проявляться и в «ядре» современной капиталистической системы смогла «догнать» развитой мир, но и «развитой мир» начал развиваться слишком разнонаправленно, утрачивая часть своих социально конкурентных свойств, что сделало невозможной компенсацию разрывов только за счет опережающего развития социальных и коммуникационных технологий. Дополняет картину и очевидный кризис концепции «глобальных городов», которая была основой проектировавшегося на период после 2020 г. сетевого мира. А «сетевой мир» должен был охватывать не только развивающиеся страны, но и США [10]. «Революция Трампа» может до известной степени рассматриваться как реакция части американской элиты на попытку «сетевизации США», которая грозила утратой важных элементов американской государственности.

Социальная составляющая реиндустриализации становится ее важной компонентой, которая логично должна привести к воссозданию тех центров социальной кристаллизации и консолидации, которые естественным образом формируются вокруг промышленных ядер. Справедливости ради следует отметить наличие сомнений в «креативном классе» как в носителе новой экономической идеологии и в его способности выполнять функции инструмента консолидации социального пространства. За этим стоит признание социальной атомизации после определенного предела опасным явлением, которое не компенсируется развитием социальных интегрированных коммуникаций.

Принципиальным моментом для будущей конфигурации системы глобальных политических отношений является «точка сборки» того, что можно назвать «постидеологией постконсерватизма» и что может стать противостоящим, балансирующим фокусом для идеологии «неограниченного глобализма», которая сейчас переживает очевидный кризис. Идеология начинает рассматриваться как вполне допустимый инструмент управления «большими системами», причем не только государством [12]. Социальная хаотизация становится той новой реальностью, через которую в той или иной степени приходится проходить многим странам и которая начинает считаться почти неизбежным спутником процессов глобальной реструктуризации [21].

\footnotetext{
${ }^{6}$ Показателем этого становятся участившиеся призывы экономистов и социологов классического западного мейнстрима к «возвращению к истокам» классического капитализма с целью поднятия его конкурентоспособности. В качестве отправной точки усреднения-стагнации рассматривается насыщение экономики и социальной сферы технологиями, сделавшими высокую квалификацию отдельного человека и даже некоторых социальных групп избыточными [8, с. 14-15]. Еще более радикальные мысли звучат в книге Паскаля Салена «Вернуться к капитализму, чтобы избежать кризисов» [11]. Западная научная мысль с разных сторон подходит к идее об исчерпанности возможностей «социального капитализма» особенно с точки зрения его конкуренции с азиатскими экономиками.
} 
Для России социальная реструктуризация является важнейшим вызовом. И не исключено, что в рамках попытки дать ответ на этот вызов России удастся сформулировать некие подходы как минимум частично альтернативные классической западной модели социального устройства. И эти подходы могут оказаться для многих стран куда более приемлемыми, нежели «азиатский», который ассоциируется с Китаем, или «постхристианский», который пытался продвигать ЕС.

Пока Москва публично действует по данному направлению крайне неохотно, поскольку в российских общественно-активных слоях общества, равно как и в элите, сохраняется аллергия и стратегическое недоверие к любым формам идеологии, пусть даже к усеченным по своему значению идеологическим конструктам. Но в том, что касается развития социальных структур в рамках новых поведенческих моделей и практик, в России накоплен колоссальный опыт как отрицательный, так и положительный. В России сложились наиболее эффективные механизмы противодействия эффекту «сетевых революций», которые на деле оказываются инструментами управляемой и сфокусированной социальной деструкции привычных социальных институтов.

Новая информационная среда. Современное «информационное общество» окончательно трансформировалось в соответствии с форматами и особенностями технологий интегрированных коммуникаций, которые обеспечивают высокий уровень социальной интрузивности. Интегрированныекоммуникацииобладаютзначительнымпотенциаломнетолькоинформационного, но и социального воздействия, выходящего далеко за рамки одного лишь коммуникационного пространства и реализуя принцип максимального социального воздействия участия в социальнокоммуникационных пространствах (анклавах) при минимизации индивидуального воздействия участника коммуникационного процесса на формирование информационного потока. Процесс глобализации информационных потоков на базе цифровых информационных технологий достиг пика своего развития. Парадокс ситуации заключается в том, что интегрированные коммуникации, возникнув как сетевая, контентно-дисперсная система, с самого начала стали воспроизводить в себе принципы институциональности (группы, сообщества). А затем как реакция на институционализацию, начались попытки хотя бы сегментарной иерархизации пространства и внедрения в него регулятивных механизмов (это проявляется в том числе в развитии сети «Фейсбук»), в различной степени контролируемых государственными органами․

Встает вопрос о принципиальной возможности реализации классического сценария безграничной сетевизации информационного пространства [19] и перспективах сохранения глобального информационного общества как единого в операционном и регулятивном плане феномена. Можно полагать, что уже в ближайшей перспективе на глобальном уровне на фоне процессов регионализации глобальной торговли и расчетных механизмов (механизмов новых финансовых коммуникаций) возникнет новый глобальный дискурс относительно будущего информационного общества.

Формирование новой парадигмы информационного общества - это пока что единственная глобальная тенденция, в которой Россия и не играет решающей роли, и пока не предложила какой-то самостоятельной модели развития. Хотя именно с действиями России связываются многие решения, уже сейчас существенно изменившие характер мировых процессов. Россия освоила ключевые технологии управления социальными процессами с использованием интегрированных коммуникаций, включая и технологии манипулирования. Но самостоятельного видения перспектив развития информационного общества не она предложила, ограничившись интерпретациями западных подходов.

Это отражает сложившуюся в российской элите точку зрения о вторичности, прикладной сущности информационного пространства по отношению к экономическому и политическому, что является ошибкой, но отражает объективные сложности с формированием контролируемой системы каналов современных цифровых коммуникаций, остающиеся под контролем США и аффилированных с ними институтов. Данное положение тем более странно, что даже в советский период в нашей стране разрабатывались оригинальные концепции развития информационного общества в его социальных, а не чисто технологических проявлениях [2].

\footnotetext{
7 Важным свидетельством концептуального кризиса ранее практически монопольно господствовавшей концепции «неограниченного сетевого информационного общества» следует считать появление таких текстов, как статья Найла Фергюсона «Ложное пророчество о гиперсвязанном мире» [14], хотя большие сомнения в том, что коммуникационная цифровая связность сможет в полной мере заменить связность социальную [9], возникали и раньше.
} 
Одновременно Россия и по данному направлению становится крупнейшим игроком. Процессы и пропагандистские фантомы, связанные с Россией, стали одними из наиболее важных стимулов для пересмотра ранее считавшихся незыблемыми подходов США к управлению глобальным информационным обществом, выявив ранее скрытые манипулятивные механизмы (очевидна прямая связь между делом о якобы имевшем место взломе серверов Демократической партии США и фундаментальным по своим последствиям «делом компании Cambridge Analytica»). Проблема не только в том, что Россия смогла освоить и сравнительно успешно применять те технологии, которые рассматривались как исключительное интеллектуальное достояние Запада: оная продемонстрировала новую модель диалектики информационного и социального в современном цифровом информационно обществе. И эта модель оказалась для Запада неожиданной прежде всего потенциалом глобализируемости и масштабируемости.

Однако и в проблематике стратегического развития глобального информационного пространства имеется значимый «российский фактор». Сохранение России в пространстве глобальных коммуникаций, прежде всего глобальных финансовых коммуникаций, и расчетных систем, равно как и отсутствие пока что решительных движений в этом направлении отражают неготовность «коллективного Запада» к исключению России не только и не столько из международного финансово-инвестиционного пространства, сколько из международного информационного пространства. Такие действия будут неизбежно связаны с рестриктивным изменением существующего формата глобального информационного общества, прежде всего его глобализированной сетевой составляющей. Любые действия по ограничению присутствия России в глобальном информационном пространстве (хотя бы в сегменте глобальных финансовых коммуникаций) могут оказаться дополнительным толчком к национализации и регионализации глобального информационного пространства, пока сдерживаемыми специфичностью имеющихся прецедентов (Китай, КНДР и проч.). А ведь сохранение относительно свободного и, безусловно, глобального информационного пространства является одной из основ сохранения, пусть даже в редуцированной форме, американской глобальной монополярности, а также доминирования в глобальной политике (в сфере перспективных политических моделей) «коллективного Запада».

\section{ВМЕСТО ЗАКАЮЧЕНИЯ}

Вероятнее всего, мы присутствуем при закате того «плоского мира» [17], который служил ключевой моделью развития глобального экономического, а как результат и - политического пространства на протяжении последних лет, и возврате к более «рельефным» и существенно менее сетевизированным моделями международных отношений. «Плоская» глобальная политическая и социо-культурная архитектура перестала отвечать новым реалиям. Главный вопрос: кто и как будет участвовать в формировании новых институциональных правил игры и нового мирового порядка, ибо крушение прежнего уже признано [20]? Фактором, который дополнит уже в самом ближайшем времени описанные выше векторы трансформаций, станет асимметрия социокультурного развития, включая и асимметрии социально, а не биологически обусловленного потребления. Это начинает рассматриваться как исключительно серьезная угроза современным тенденциям в глобализации [18].

Отметим три важнейших обстоятельства.

Во-первых, реализация потенциала хотя бы части обозначенных векторов развития означает стратегическую перестройку не просто отдельных сегментов системы международных отношений, но их архитектуры, системы институтов, обеспечивающих ограничение форм и методов экономической конкуренции, снижение уровня политической конфликтности и исключение наиболее жестких форм прямой силовой конфронтации между ключевыми игроками.

Во-вторых, Россия оказывается далеко не последним игроком в сложном маневрировании ключевыхдержавмиравборьбезаправорешающегоголосавопределенииновой институциональной архитектуры глобальной политики и экономики. Россия оказывается слишком плотно вписана в большинство реализующихся в глобальном формате тенденций. Как минимум, в пяти из шести векторов развития Россия может сыграть если не решающую, то очень важную роль, становясь «гирькой», склоняющей чашу весов в ту или иную сторону. Присутствие России в этом равновесии, однако, превращает существующее геоэкономическое (и геополитическое) противоборство в «игру с ненулевой суммой», поскольку у участников процесса существует надежда на то, ито их уступки могут быть компенсированы за счет России. 
B-третьих, к решительной перестройке системы международных отношений пока не готова ни одна значимая геополитическая сила современности, что обеспечивает тактически выигрышные позиции для США, которые - единственные из всех ключевых геополитических сил - имеют возможность действовать в рамках модели «конфликта с ненулевой суммой», хотя они и ограничены в своих возможностях компромисса теми пропагандистскими конструктами, которые сами же создали из тактических соображений, став ныне их заложниками. В таких условиях велика вероятность того, что ключевые участники геополитических процессов, стремясь сохранить ситуацию в рамках «модели с ненулевой суммой», будут использовать Россию как минимум в качестве своего рода «буфера», а как максимум в качестве объекта, «приза», за счет которого будут компенсироваться уступки, сделанные друг другу в ходе «торгов».

Россия является одним из немногих игроков, которые имеют реальную возможность влиять на выработку стратегических решений по будущей глобальной политике и экономике, где сейчас, в период неопределенности по стратегическим решениям, ставки исключительно велики. Когда ключевые стратегические решения будут приняты и речь пойдет о конкретных механизмах и «долях влияния, роль России, если она не сможет сформировать вокруг себя глобальную значимую систему экономических отношений и технологических связей, будет уменьшаться. Для реализации имеющихся возможностей Россия должна получить институциональную (то есть проявляющуюся в системных связях) субъектность и допустить для себя в ряде случаев «игру первым номером». Иными словами - возглавить те или иные глобальные процессы.

Конфронтация «коллективного» Запада (в данном случае эта метафора допустима) с Россией - это не просто борьба за увеличение своей «доли» в глобальном политическом и экономическом «пироге». Это - борьба за влияние на процесс формирования новой архитектуры глобальной экономической и политической системы. Это борьба за то место, которое займет та или иная страна в новой глобальной институциональности, которая неизбежно сформируется, когда мир, приобретший несвойственную ему ранее динамику, снова начнет «затвердевать». Эта борьба ведется и на национальном, и на коалиционном уровне (примером чего является ситуация внутренней конкуренции в рамках ЕС), поэтому понятие «коллективный Запад» уже сейчас применимо лишь частично. Это борьба за влияние на стадии формирования обновленных «правил игры», которые доминирующая сила, даже если ею останутся США, уже не сможет нарушать столь безоглядно, как сейчас, на этапе распада актуальной пока версии глобализации. Эта борьба со стороны Запада ведется максимально конфронтационно, поскольку утрата хотя бы части внешнего влияния, «ареала экономического и политического вовлечения», означает необходимость изменения внутреннего состояния как «коллективного Запада» в целом, так и отдельных национальных его составляющих. Что может иметь непредсказуемые последствия.

«Коллективный Запад» не допускает, чтобы Россия играла значимую самостоятельную роль в процессе выработки новых правил игры, предотвращая присоединение Москвы к альтернативным западным проектам по ключевым направлениям развития, что может привести к изменению равновесия. Естественная логика в таком случае - попытаться в принципе исключить влияние России на глобальные процессы, загнав ее в ловушку конфронтации и спровоцировав на действия, которые сделают ее изоляцию, хотя бы даже и временную - на 5-7 лет, оправданной и естественной. После чего Россия может быть вновь возвращена в «семью», но уже на более сложных условиях. (Ее нынешнее взаимодействие с олимпийским движением может рассматриваться здесь как модель). Но одновременно Запад не может позволить существования альтернативной модели построения новой глобальной архитектуры. Россия, не имея возможности однозначно выбирать сторону в глобальной конкуренции, что одномоментно девальвирует ее значимость, придерживается стратегии выжидания, сохраняя приемлемый уровень внутренней социальной стабильности, что с учетом санкционной политики «коллективного Запада» следует считать большим достижением.

У Москвы все больше стимулов, чтобы выступать в качестве одного из лидеров группировки средних стран, которые будут ощущать себя некомфортно в условиях, когда и если противоборство приобретет жесткие формы. Это могут быть не только классические «страны-изгои» или близкие к ним геополитические маргиналы [7], тем более что теперь само это понятие утрачивает актуальность, но и вполне «респектабельные» страны, элиты которых видят тупиковость попыток обеспечить свои экономические интересы в рамках существующей архитектуры международных отношений и которые по тем или иным причинам могут оказаться «назначенными жертвами» в ходе кардинальной перестройки мирового политического и экономического пространства, 
в силу чего заинтересованы в эволюционности процесса перемен, особенно политических и военно-политических, а также в диалогичности этого процесса. Россия почти неизбежно до известной степени будет выступать как «таран» и «громоотвод» В глобальной политике, но события 2008-2017 гг. приучили российское общество к тому, что такой статус для него неизбежен и что он в принципе при определенных политических условиях может быть монетизирован.

\section{АИТЕРАТУРА}

1. Алексеева Т. А., Минеев А. П., Лошкарев И. Д. «Земля смятения»: квантовая теория в международных отношениях»? // Вестник МГИМО-Университета. - 2016. - № 3. - С. 7-16.

2. Афанасьев В. Г. Человек: общество, управление, информация. Опыт системного подхода. - М.: Книжный дом «Либроком», 2013. - 208 с.

3. Дзоло Д. Демократия и сложность. Реалистический подход. Пер. с англ. - М.: Издательский дом ВШЭ, 2010. - $320 \mathrm{c}$.

4. Евстафьев Д. Нефтеюань: экономическая реальность против политических иллюзий // Инвест-Форсайт. - 2018. - 24 января. - URL: https://www.if24.ru/nefteyuan-realnost-protiv-illyuzij

5. Евстафьев Д. Четвертая промышленная революция: пропагандистский миф или «знак беды»?» // ИнвестФорсайт. - 2017. - 12 октября. - URL: https://www.if24.ru/4-promyshlennaya-revolyutsiya-mif

6. Захаров А. Н. Перспективы реиндустриализации развитых экономик (США, Канада и Австралия) // Вестник МГИМО-Университета. - 2018. - № 1. - С. 213-245.

7. Кортунов А. Чего ты хочешь, Джон? К чему приведет противостояние России и США // Московский центр Карнеги. - 2018. - 26 апреля. - URL: https://carnegie.ru/commentary/76145

8. Коуэн T. Среднего более не дано. Как выйти из эпохи Великой стагнации. Пер. с англ. - М.: Изд-во Института Гайдара, 2015. - 320 с.

9. Ланир Дж. Вы не гаджет. Манифест. Пер. с англ. - М.: Астрель; Corpus, 2011. - 320 с.

10. Пилька М. Э., Слука Н. А. Глобальные города США как хабы зарубежных ТНК // Вестник МГИМОУниверситета. - 2017. - № 6. - С. 196-206.

11. Сален П. Вернуться к капитализму, чтобы избежать кризисов. Пер. с франц. - М.: Изд-во Института Гайдара, 2015. - 272 с.

12. Соловьев А. И. Дискурсы и праксисы: может ли идеология помочь в управлении государством? // Полития. - 2018. - № 1. - С. 7-29.

13. Стратегический сценарный прогноз: Пермский край, Россия и мир - 2030 / Под общ. ред. А. И. Агеева. М.: Институт экономических стратегий РАН; Рубин, 2016. - 432 с.

14. Фергюсон Н. Ложное пророчество о гиперсвязанном мире [In Eng.: The False Prophecy of Hyperconnection. How to Survive the Networked Age. Foreign Affairs. 2017. No. 5]. Россия в глобальной политике. - 2018. - № 1.

15. Франкопан П. Шелковый путь. Пер. с англ. - М.: Эксмо, 2018. - 688 с.

16. Daalder I., Lindsay J. The Empty Throne. American Abdication of Global Leadership. - New York: Public Affairs, 2018. $-239 \mathrm{p}$.

17. Friedman T. The World is Flat. A Brief History of the Twenty First Century. - New York: Farrar; Straus and Giraux, 2005. - 488p.

18. Fukuyama F. Against Identity Politics. The New Tribalism and the Crisis of Democracy // Foreign Affairs. - 2018.

- September/October.

19. Jenkins H., Ford S., Green J. Spreadable Media. Creating Value and Meaning in a Networked Culture. - New York: New York University Press, 2013. - 352 p.

20. Haas R. How a World Order Ends. And What Comes in Its Wake // Foreign Affairs. - 2019. - January/February.

21. Kaplan R. D. The Anarchy that Came // The National Interest. - 2018. - October 21.

22. Lind M. America vs. Russia and China: Welcome to Cold War II // The National Interest - 2018. - April 15. 


\title{
DMITRY EVSTAFIEV
}

\section{Global Transformations and Russia: the Sources of Confrontation and Prospects for Cooperation}

\author{
Dmitry Evstafiev, PhD in Political Science, \\ Professor, Department for Integrated Communications, \\ Faculty of Communications, Media, and Design, \\ National Research University - Higher School of Economics. \\ E-mail: devstafiev@hse.ru; estd1212@yandex.ru
}

\begin{abstract}
Summary. Increased and diversified tensions in Russian-Western relations and first Russian-American relations are not only a result of propaganda pressure. They also reflex a number of conflicting realities of the contemporary system of international political and economic relations that involve Russia as an important player. The role of Russia is especially noticeable now that the process of development of the architecture of a new global system is underway. Hostile or confrontational position of Russia could be a major risk as well as a factor that can change the strategic context of the global competition. The emerging system looks much different from the one that formed the basis on which the world developed during the last 30 years. In that environment a potential hostile position of Russia is regarded as a major risk. But the active involvement of Russia into most important recent global economic and political developments prevents the situation of surpassing the limits of the «non-zero sum game».

Keywords: Russia, the USA, new Cold War, globalization, military confrontation, global financial system, energy security, global institutes.
\end{abstract}

\section{REFERENCES}

Alekseyeva T. A.., Mineev A. P., Loshkariov A. P. "Zemlya Smyatenija”: Kvantovaja Teorija v Mezhdunarodnykh Otnoshenijakh? ["Land of Confusion": Quantum Physics in IR Theory?]. Vestnik MGIMO-Universiteta. 2016. No. 2. P. 14-21.

Afanasiev V. G. Chelovek: Obshchestvo, Upravlenije, Informatsija. Opyt Sistemnogo Podkhoda [The Person: Society, Governance, Information. An Essay in Systemic Approach]. Moscow: Publishing house LIBRICOM, 2013. 208 p.

Cowen T. Srednego Boleje ne Dano: Kak Vyjti iz Epokhi Velikoj Stagnatsiji [Average is Over. Powering America Beyond the Age of Great Stagnation. Transl. from English]. Moscow: Publishing House of Gaidar Institute, 2015. 320 p.

Daalder I., Lindsay J. The Empty Throne. American Abdication of Global Leadership. New York: Public Affairs, 2018. 239 p.

Evstafiev D. Nefteyuan': Ekonomicheskaja Real'nost' Protiv Politicheskikh Illusij [Oil Yuan: The Economic Reality Against Political Illusions]. Invest-Foresight, January 24, 2018. - URL: https://www.if24.ru/nefteyuan-realnost-protiv-illyuzij

Evstafiev D. Chetvertaja Promyshlennfa Revolutsija: Propagandistskij Mif ili “Znak Bedy”? [The Forth Industrial Revolution: a Propaganda Myth or a "Sign of a Catastrophy]. Invest-Foresight, October 12, 2017. - URL: https://www. if 24.ru/4-promyshlennaya-revolyutsiya-mif/

Ferguson N. Lozhnoje Prorochestvo v Gipersv'yzannom Mire [The False Prophecy of Hyperconnection. How to Survive the Networked Age. Trans. in Russ.]. Rossiya v global'noy politike. 2017. No. 5.

Frankopan P. Shelkovyj Put' [The Silk Road: A New History of the World.] Transl. from English. Moscow: Publishing House Exmo, 2018. 688 p.

Friedman T. The World is Flat. A Brief History of the Twenty First Century. New York: Farrar, Straus and Giraux, 2005. $488 \mathrm{p}$.

Fukuyama F. Against Identity Politics. The New Tribalism and the crisis of democracy. Foreign Affairs. 2018. September/October. 
Haas R. How a World Order Ends. And What Comes in Its Wake. Foreign Affairs. 2019. January/February.

Jenkins H., Ford S., Green J. Spreadable Media. Creating Value and meaning in a Networked culture. New York: New York University Press, 2013. 352 p.

Kaplan R.D. The Anarchy that Came. The National Interest. 2018. October 21. - URL: https://nationalinterest.org/ feature/anarchy-came-33872

Kortunov A. Chego Ty Khochesh, Dzhon? K Chemu Privedet Protivostojanije Rossiiji I SShA? [A Letter to John: Where Are U.S.-Russia Relations Headed?]. Moscow Carnegie Center, April 26, 2018. - URL: https://carnegie.ru/ commentary/76145

Lanier J. Ty ne Gadzhet. Manifest [You are not a Gadget. A Manifesto. Transl. from English]. Moscow: Astrel Publishing House; Corpus, 2011. 320 p.

Lind M. America vs. Russia and China: Welcome to Cold War II. The National Interest. 2018. April 15. - URL: https:// nationalinterest.org/feature/america-vs-russia-china-welcome-cold-war-ii-25382

Pilka M., Sluka M. Global'nyje Goroda SShA kak Khaby Zarubezhnykh TNK [US Global Cities as Hubs for Foreign Transnational Corporations]. Vestnik MGIMO-Universiteta. 2017. No. 6. P. 196-206.

Salin P. Vernut'sja k Kapitalizmu chtoby izbezhat' Krizisov [Revenir au capitalisme Pour éviter les crises. Transl. from French]. Moscow: Publishing House of Gaidar Institute, 2015. 272 p.

Solov'ijov A. I. Diskursy I Praksisy: Mozhet li Ideologija Pomoch’ v Upravleniji Gosudarstvom? [Discourses and Practices: Whether Ideology can Contribute to Public Administration»] // Politeia. 2018. No. 1. P. 7-29.

Strategiceskij Stsenarnyj Prognoz: Permskij Kraj. Rossija i Mir [Strategic Scenario Prognosis. Perm Region, Russia and the World 2030]. A. I. Ageev (ed.). Moscow: Institute for Economic Strategies of the Russian Academy of Sciences; Rubin Publishing House, 2016. 432 p.

Zakharov A. N. Perspektivy Reindustrializatsii Razvitykh Economik (SShA, Kanada i Avstralija) [Prospects For the Re-Industrialization of Developed Economies (USA, Canada and Australia)]. Vestnik MGIMO-Univarsiteta. 2018. No. 1. P. 213-245.

Zollo D. Demokratija I Slozhnost'. Realisticheskij Podkhod [Democracy and Complexity. A realist Approach. Transl. from English]. Moscow: Publishing House of the State University Higher School of Economics, 2010. 320 p. 